\title{
Biocontrol evaluation of extracts and a major component, clusianone, from Clusia fluminensis Planch. \& Triana against Aedes aegypti
}

\author{
Maria C Anholeti ${ }^{1,2}$, Rodrigo C Duprat ${ }^{3}$, Maria R Figueiredo ${ }^{4}$, Maria AC Kaplan ${ }^{5}$, Marcelo Guerra Santos ${ }^{6}$, \\ Marcelo S Gonzalez ${ }^{3}$, Norman A Ratcliffe ${ }^{3,7}$, Denise Feder ${ }^{3}$, Selma R Paiva ${ }^{2}$, Cicero B Mello ${ }^{3 /+}$ \\ ${ }^{1}$ Universidade Federal do Rio de Janeiro, Instituto de Pesquisas de Produtos Naturais, Programa de Pós-Graduação em Química de Produtos \\ Naturais, Rio de Janeiro, RJ, Brasil ${ }^{2}$ Universidade Federal Fluminense, Instituto de Biologia, Laboratório de Botânica Estrutural e Funcional, \\ Niterói, RJ, Brasil ${ }^{3}$ Universidade Federal Fluminense, Laboratório de Biologia de Insetos, Niterói, RJ, Brasil ${ }^{4}$ Fundação Oswaldo Cruz, \\ Farmanguinhos, Laboratório de Química de Produtos Naturais, Rio de Janeiro, RJ, Brasil ${ }^{5}$ Universidade Federal do Rio de Janeiro, \\ Instituto de Pesquisas de Produtos Naturais, Rio de Janeiro, RJ, Brasil ${ }^{6}$ Universidade do Estado do Rio de Janeiro, Faculdade de Formação de Professores, \\ Departamento de Ciências, Rio de Janeiro, RJ, Brasil 'Swansea University, College of Science, Department of Biosciences, Swansea, UK
}

Studies evaluated the effects of hexanic extracts from the fruits and flowers of Clusia fluminensis and the main component of the flower extract, a purified benzophenone (clusianone), against Aedes aegypti. The treatment of larvae with the crude fruit or flower extracts from C. fluminensis did not affect the survival of Ae. aegypti $(50 \mathrm{mg} / L)$, however, the flower extracts significantly delayed development of Ae. aegypti. In contrast, the clusianone (50 $\mathrm{mg} / \mathrm{L}$ ) isolate from the flower extract, representing 54.85\% of this sample composition, showed a highly significant inhibition of survival, killing 93.3\% of the larvae and completely blocking development of Ae. aegypti. The results showed, for the first time, high activity of clusianone against Ae. aegypti that both killed and inhibited mosquito development. Therefore, clusianone has potential for development as a biopesticide for controlling insect vectors of tropical diseases. Future work will elucidate the mode of action of clusianone isolated from $\mathrm{C}$. fluminensis.

Key words: clusianone - larvicidal - Clusia fluminensis - Aedes aegypti

Many insecticides, including the organochlorines, organophosphates and carbamates, persist in the environment as toxic waste (Miresmailli \& Isman 2014) and are neurotoxic not only to humans, but to livestock too (Narahashi 2000, Biondi et al. 2012). Furthermore, the redundant mode of action of insecticides may accelerate the emergence of cross-resistance to other pesticides (Georghiou 1972, Miresmailli \& Isman 2014). Therefore, new approaches for insect control need evaluating, including substances from natural sources that may have less of an environmental impact (Isman 2006).

One example of a pest species that is a major vector of human diseases, including urban yellow fever, dengue, Chikungunya and Zika virus is Aedes aegypti, for which there are also many reports of populations developing resistance to different insecticides (Braga et al. 2004, Vontas et al. 2012). Ae. aegypti has a cosmopolitan distribution, is highly domesticated and anthropophilic (Gubler 2011, Powell \& Tabachnick 2013). It is estimated that 3.6 billion people live in areas at risk from dengue infection and 390-500 million cases occur in 124-128 countries worldwide each year (Beatty et al. 2010, Brady et al. 2012,

doi: 10.1590/0074-02760150103

Financial support: PROPPI-UFF, CNPq, FAPERJ

MCA and RCD contributed equally to this work.

+ Corresponding author: cicerobrasileiro@globo.com

Received 15 March 2015

Accepted 24 June 2015
Bhatt et al. 2013). In Brazil, the current distribution of $A e$. aegypti extends to almost the whole country (Braga \& Valle 2007), causing cyclic outbreaks of dengue fever in various regions, in which there are four main serotypes of the virus in circulation (Bastos et al. 2012, Dick et al. 2012). There is neither a vaccine nor specific treatment for dengue (Bhatt et al. 2013), so that combating the virus is limited to elimination of the mosquito vector (Beatty et al. 2010, Dick et al. 2012). Therefore, the search for new alternative strategies and increased vigilance for vector resistance have become essential for the control of this disease (Maciel-de-Freitas et al. 2014).

Many plant natural products have been tested as insecticides against mosquitoes (Carvalho 2011, Miresmailli \& Isman 2014, Reegan et al. 2014) as they are nontoxic to mammals and are promising candidates to replace conventional insecticides to which insects are becoming more resistant (Braga et al. 2004, Shaalan et al. 2005, Cantrell et al. 2012, Vontas et al. 2012). In the majority of these studies, although larvicidal activity has been described for the extracts and the presence of a range of compounds sometimes detected, very few have actually identified the compounds responsible for activity together with their structure (Navarro et al. 2015). Some of the compounds identified have been shown to disrupt the insect endocrine system, acting as agonists or antagonists of insect hormones, killing or even preventing them reaching the adult stage (Bowers et al. 1976, Garcia et al. 1986). One group of such natural plant insecticides includes the terpenes, that are related to terpenoids with insect juvenile hormone $(\mathrm{JH})$ analogue activity and have been commercially used successfully as substitutes for classical insecticides in areas where insect resistance 
has been detected (Braga et al. 2005a,b). Apparently, no cross-resistance occurs between $\mathrm{JH}$ analogues and the pyrethroids which are generally used for the control of Ae. aegypti (Braga et al. 2005a).

Scientists, however, need to increase the number of alternative natural insecticides available for the control of Ae. aegypti in order to build up an arsenal of natural products able to counter the resilience of these mosquitoes to develop resistance. Thus, another group of natural pesticides derived from plants with potential as insect control agents are the benzophenones. Many derivatives of these compounds with different structures and a multiplicity of functions have been described (Beerhues \& Liu 2009, Li et al. 2014). Very few of these compounds have been investigated as potential insect control agents, although the insecticidal activity of benzophenones has been known for many years (Middleton \& Chadds 1973). Only recently has their mosquito larvicidal activity been realised with synthetic benzophenone indole analogues (Ranganatha et al. 2013) and with the benzophenones, cariphenone A and cariphenone B, isolated from a Hypericum carinatum (da Silva et al. 2013a). In addition, a commercial preparation of benzophenones used in ultraviolet (UV) filters has been shown to disrupt the endocrine system, activating hormonal genes and altering embryonic development of Chironomus riparius (Ozáez et al. 2014).

One source of benzophenones is Clusia fluminensis (Planch. \& Triana) (Clusiaceae), a native species from the Brazilian coast, commonly used as an ornamental plant because of its evergreen leaves and high tolerance to dehydration. Significantly, these leaves rarely show signs of herbivory, which are always undamaged and bright (Bittrich 2010). In 2000, Porto et al. identified and quantified, by high performance liquid chromatography, polyisoprenylated benzophenones, including clusianone and spiritone, in resins obtained from the male flowers of $C$. fluminensis. Recently, clusianone from male flowers of C. fluminensis was also isolated and structurally characterised (Silva et al. 2012).

In the quest for alternative natural biological control agents against mosquito larvae, the present paper reports on the larvicidal activity of hexanic extracts from C. fluminensis against Ae. aegypti (Linnaeus) (Diptera: Culicidae). Subsequently, a benzophenone (clusianone) was isolated, structurally elucidated and investigated as the source of the larvicidal activity.

\section{MATERIALS AND METHODS}

Insect colonies - Eggs of Ae. aegypti, Rockefeller strain, were provided by Dr José Bento Pereira Lima [Brazilian Army Biology Institute, Oswaldo Cruz Foundation (Fiocruz), state of Rio de Janeiro (RJ), Brazil]. They hatched in the rearing water after about $1 \mathrm{~h}$ and groups of 500 newly hatched larvae were placed in plastic bowls $(25 \times 15 \times 7 \mathrm{~cm})$ containing $500 \mathrm{~mL}$ of dechlorinated water and $500 \mathrm{mg}$ of fish feed flakes (Tetramin ${ }^{\circledR}$ Tropical Flakes). The larvae were kept in incubators BOD at $26 \pm$ $1^{\circ} \mathrm{C}$ until third instars emerged after approximately $72 \mathrm{~h}$.

Plant material - Flowers from male and fruits from female $C$. fluminensis were collected, with the permis- sion of the Brazilian Army, in a rocky outcrop at Forte Barão do Imbuhy, in the city of Niterói, RJ. Flowers and fruits were available in the summer of 2006 and autumn of 2007, respectively. The plant material was identified by Dr Marcelo Guerra Santos and a voucher specimen was deposited at the herbarium of the Faculty of Teacher Education, Rio de Janeiro State University (licence 9213).

Preparation of plant extracts - Fruits of $C$. fluminensis were dried in an oven at $40^{\circ} \mathrm{C}$ and subsequently fragmented while whole flowers were used while still partially fresh. The crude extracts were prepared by macerating plant organs with analytical grade hexane as a solvent at room temperature. The solvent was renewed every seven days and then evaporated under reduced pressure.

Chemical analysis of crude extracts - Gas chromatography coupled with mass spectrometry (GC-MS) The crude extracts obtained from flowers of $C$. fluminensis were analysed by GC-MS performed on an Agilent model $6890 \mathrm{~N}$ gas chromatograph equipped with a mass selective detector, model $5973 \mathrm{~N}$. A volume of $1 \mu \mathrm{L}$ of the solution with a concentration $1 \mathrm{mg} / \mathrm{mL}$ was injected. The following conditions were utilised: carrier gas, helium at $2.0 \mathrm{mLmin}^{-1}$, split ratio 5:1, injector temperature $300^{\circ} \mathrm{C}$ and ion source temperature $230^{\circ} \mathrm{C}$. The oven temperature was programmed from $150-300^{\circ} \mathrm{C}$ at $10^{\circ} \mathrm{C} \mathrm{min}^{-1}$ and held at $300^{\circ} \mathrm{C}$ for $15 \mathrm{~min}$. Sample injection volume was $1 \mu \mathrm{L}$. The mass spectra of the major components of $C$. fluminensis flowers were analysed and compared with the Wiley mass spectral databases and the literature data.

Nuclear magnetic resonance (NMR) analysis - The NMR spectra were acquired using a BRUKER DRX 400 spectrometer operating at $400 \mathrm{MHz}$ for ${ }^{1} \mathrm{H}$ and 100 $\mathrm{MHz}$ for ${ }^{13} \mathrm{C}$. Chemical shifts were measured relatively to an internal tetramethylsilane reference. Spectral data of clusianone was published for our group previously in Silva et al. (2012) and the purification and identification of lanosterol in Oliveira et al. (2014). The structure of lanosterol was confirmed by MS compared to the equipment's database (Wiley Database) and NMR.

Isolation of clusianone - The polyisoprenylated benzophenone, clusianone, was isolated as a tautomeric pair from the crude hexanic extract of flowers of $C$. fluminensis by countercurrent chromatography using the solvent system n-hexane-acetonitrile-methanol (2:1.25:0.5, $\mathrm{v} / \mathrm{v} / \mathrm{v}$ ), as described by Silva et al. (2012). The material under study is endotoxin free.

Insect bioassays - Ae. aegypti larvae were used three days after hatching and were formed into groups of 10 larvae in the third instar with six replicates. The groups were placed in $300 \mathrm{~mL}$ disposable plastic cups containing $50 \mathrm{~mL}$ of dechlorinated water. The cups were then randomly allocated to groups, with the aid of the pwgen (Windows Phone) program. The dried extracts and isolates were weighed and solubilised with $0.1 \%$ dimethyl sulfoxide (DMSO) to make up to $50 \mu \mathrm{L}$, with a final concentration of $50 \mathrm{mg} / \mathrm{L}$ in the water test. These substances were thoroughly mixed in the water test to minimise the possibility of adhesion of particles to the hydrophobic 
plastic surfaces. The control groups were untreated and the solvent controls (SC) were treated solely with $0.1 \%$ DMSO used to dissolve the samples. During the tests, larvae were fed with $30 \mathrm{mg}$ per cup of hamster food (Al$\operatorname{con}^{\circledR}$, Brazil), immediately after completion of the tests and three days later. The results are derived from the media of the percentage of each replicate.

All experiments were followed until the death or emergence of all insects in control group. All insects remained in the BOD incubators, at $26 \pm 1{ }^{\circ} \mathrm{C}$. Counts were made daily to evaluate dead insects and developmental stages. All experiments were repeated at least twice.

Data and statistical analysis - All graphs were created with GraphPad Prism 6.01 software (GraphPad Software, USA). The graphics analysed the survival (and mortality) and the developmental course of juvenile forms and adults. The Gehan-Breslow-Wilcoxon test compared the whole survival curves and larval and adult development (GraphPad Prism 6.01 software). No corrections for multiple comparisons were made (Rothman 1990). The Barnard's test (Barnard package v.1.3) (Erguler 2012, R Development Core Team 2014) was used to analyse the development of Ae. aegypti pupae, comparing the mean values only in a representative day indicated by an arrow in graphs. In all experiments, only $\mathrm{p}$ values $<0.05$ were considered statistically significant.

Ethics - Eggs of Ae. aegypti were provided by Dr José Bento Pereira Lima from insects treated according to the
Ethical Principles in Animal Experimentation approved by the Ethical Committee in Animal Experimentation (Fiocruz). The protocol is from National Council for the Control of Animal Experimentation/Ministry of Science, Technology and Innovation (cobea.org.br), which is associated with the American Association for Animal Science, Federation of European Laboratory Animal Science Associations, International Council for Animal Science and Association for Assessment and Accreditation of Laboratory Animal Care International. The authors declare that they have no competing interests. The funders, from Brazilian Govern, had no role in study design, data collection and analysis, decision to publish or preparation of the paper.

\section{RESULTS}

The bioassays with the hexanic extract of C. fluminensis fruit showed that in the treated groups there were no effects on the survival rates or development of $A e$. aegypti (Fig. 1 A-D).

The bioassays with the hexanic extract of C. fluminensis flowers (FL) showed no significant effect on $A e$. aegypti survival in comparison with the $\mathrm{SC}(\mathrm{p}=0.1797)$ (Fig. 2A). In contrast, the analyses of the effects of FL on the development of larvae to pupae and pupae to adults showed significant delays in molting $(\mathrm{p} \leq 0.0001)$ between the FL-treated and SC groups (Fig. 2B-D). Thus, on the fifth day, $88.3 \%$ of the SC group had molted to pupae, while $93.3 \%$ of the FL group were still in the larval
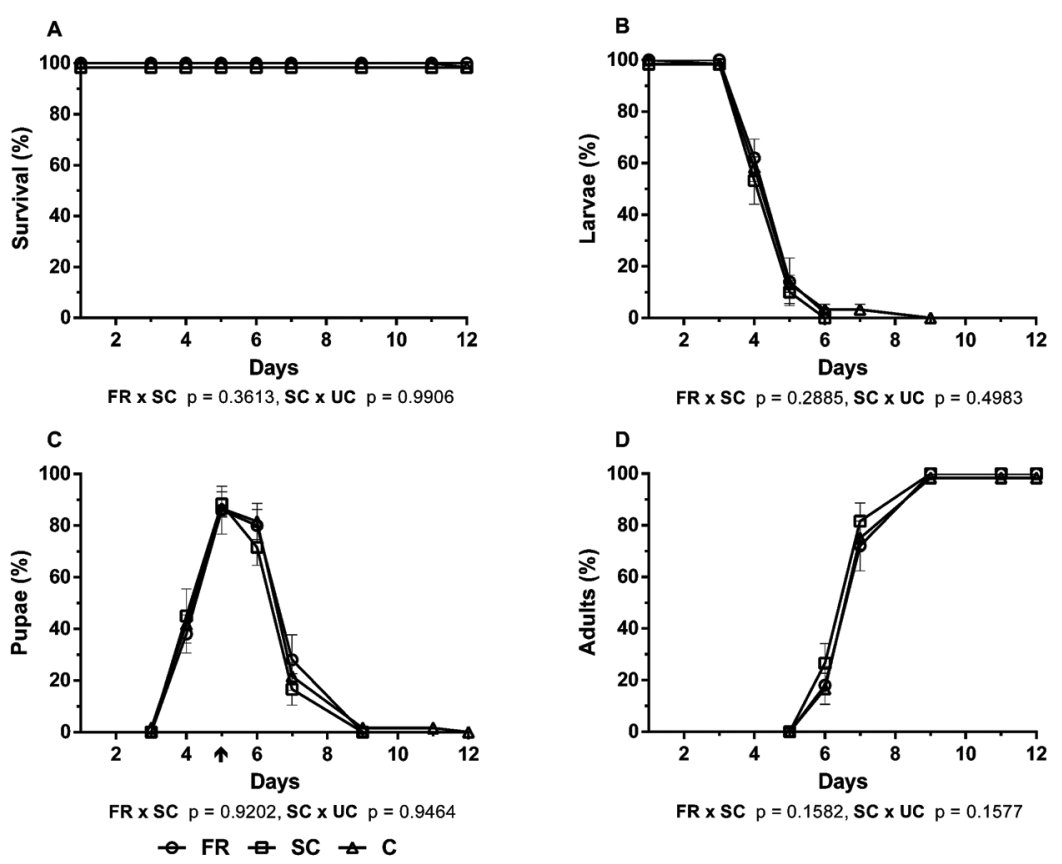

Fig. 1: effects of extracts of fruit from Clusia fluminensis (FR) on survival (A) and development of larvae (B), pupae (C) and adult (D) of Aedes aegypti at different days after experimental treatment (FR) compared with the solvent control (SC) that was compared with untreated control (UC). Each point represents the mean of at least six replicates with 10 insects and bars show standard error. Third instar Ae. aegypti larvae received $50 \mathrm{mg} / \mathrm{L}$ extract in the test water. Statistical analyses (under the graphs) with the Barnard's test were used (C) on a representative day indicated by an arrow and the Gehan-Breslow-Wilcoxon test was used (A, B, D) to compare the entire curve between the groups (FR $x$ SC and $\mathrm{SC} \times \mathrm{C}$ ). Significant differences $(\mathrm{p}$ value $<0.05$ ) are in bold. 

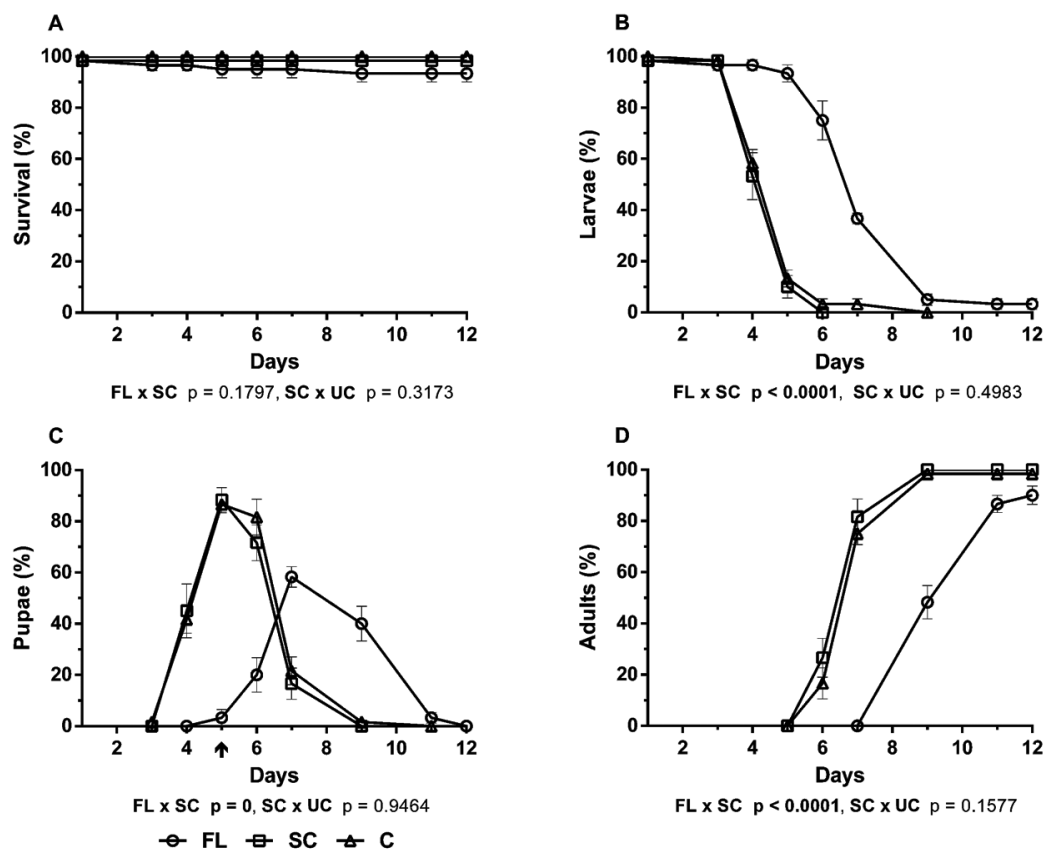

Fig. 2: effects of extracts of flower from Clusia fluminensis (FL) on survival (A) and development of larvae (B), pupae (C) and adult (D) of Aedes aegypti at different days after experimental treatment (FL) compared with the solvent control (SC) that was compared with untreated control (UC). The assays were executed and analysed as in the Fig. 1 legend and Materials and Methods.

stage (Fig. 2B, C). Furthermore, on day 7, 81.7\% of the $\mathrm{SC}$ had reached adults, while none of the FL group had reached this stage (Fig. 2D).

Since only the flower extract affected the development of Ae. aegypti, this alone was submitted to GC-MS. The chromatogram obtained for the hexanic extract of flowers of $C$. fluminensis showed that the major component (retention time: $18.424 \mathrm{~min}$ ) was the benzophenone, clusianone. This substance was identified by comparison of the mass fragmentation pattern with the data provided by Delle Monache et al. (1991) and represented 54.85\% of the hexane extract (Fig. 3). In addition, lanosterol was also detected (retention time: $19.155 \mathrm{~min}$ ) in the same extract and contributed to $9.74 \%$ of the sample composition (Fig. 3).

The purification protocols and chemical structures of clusianone from the flowers of $C$. fluminensis have been described previously (Silva et al. 2012). Subsequently, bioassays with this purified substance were performed against Ae. aegypti.

Bioassays with clusianone showed a significant reduced survival of the Ae. aegypti $(\mathrm{p}<0.0001)$ (Fig. 4A), so that by the first day of treatment $20 \%$ of larvae had already died compared with the SC group (Fig. 4A). In the clusianone-treated group, by the last day (12th) of treatment, $93.3 \%$ of insects were dead, while more than 93\% were still alive in the SC group (Fig. 4A). The few specimens of Ae. aegypti that survived the treatment with clusianone remained as larval instars (Fig. 4B), with none molting to pupae or adults (Fig. 4C, D).

In contrast with the effect of clusianone, no activity was detected by the isolated lanosterol on the survival or development of Ae. aegypti larvae in the bioassays (results not showed).

\section{DISCUSSION}

In this present study, clusianone was further identified and purified from FL, following the original protocols described by Silva et al. (2012). Clusianone is the major component from the flowers of $C$. fluminensis, representing almost $55 \%$ of the crude extract composition.

Crude fruit extracts of $C$. fluminensis had no activity on the survival or development of Ae. aegypti and preliminary results showed that clusianone is not present in these extracts, in which lanosterol is the main compound. FL also had no effects on survival, but delayed the development of Ae. aegypti. In addition, the purified clusianone not only caused high larval mortality and delayed development, but also completely blocked the molting of surviving treated-insects. These results show four important facts. Firstly, the value of analysing not only mortality, but also the effect on development in the evaluation of plant extracts activities against insects. Secondly, that fractionated and purified components may show enhanced activities in bioassays in comparison with those of crude extracts. Thirdly, the necessity of assaying different regions of the plant tissue for activity, when testing plant extracts for insecticide properties. Fourthly, they report the first description of clusianone's larvicidal activity against Ae. aegypti larvae.

The clusianone effects, however, seem to have similar characteristics to those found with synthesised benzophenone tagged indole derivatives that resulted in mortality in Culex quinquefasciatus larvae (Ranganatha et al. 2013), as well as those reported for extracts from species of Hypericum against culicids (Cetin et al. 2011). A fraction of $H$. carinatum enriched with the benzophenones, 


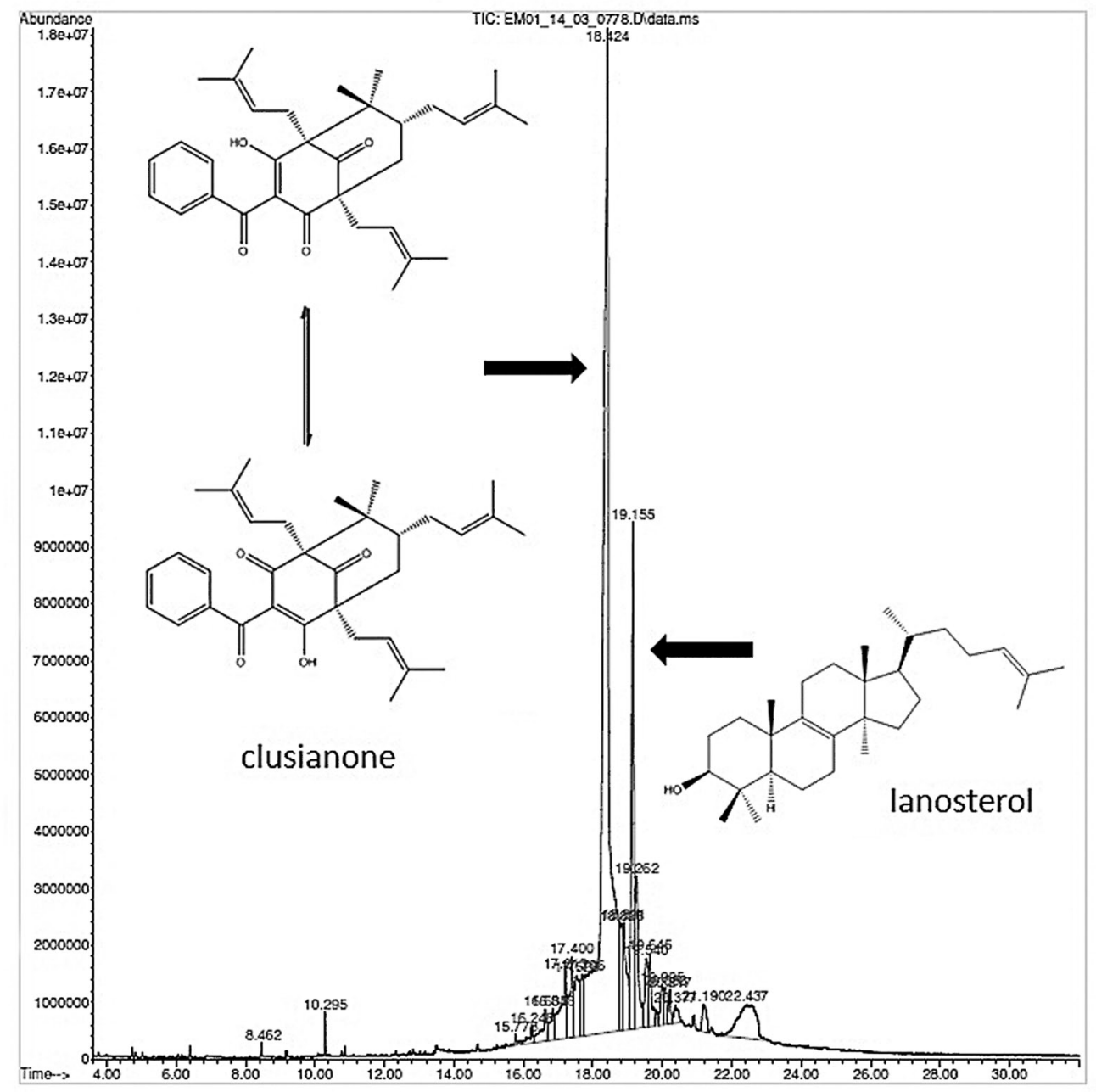

Fig. 3: chromatogram obtained for the hexanic extract of male flowers of Clusia fluminensis by gas chromatography coupled with mass spectrometry showing the benzophenone/clusianone and the triterpene lanosterol as major components.

cariphenone $\mathrm{A}$ and cariphenone $\mathrm{B}$ has also shown to have larvicidal activity against Ae. aegypti, but at a lower concentration than that used in our experiments with clusianone (da Silva et al. 2013a). The genus Hypericum is often considered to be a member of the family Clusiaceae.

Benzophenyl and benzopyran compounds, although not benzophenones, have also recently been reported to have similar effects to clusianone against mosquitoes. For example, benzophenyl urea compounds may disrupt chitin, causing changes in development or even mortality in Culex and Aedes mosquitoes in low doses (Fontoura et al. 2012, Belinato et al. 2013). Additionally, benzopyrans, present mostly in a Hypericum polyanthemum lipophilic extract, showed larvicidal activity against Ae. aegypti in high concentrations, while in sublethal levels exhibited growth-inhibiting activity to prevent pupae formation and adult emergence (da Silva et al. 2013b). This last effect was also detected with clusianone against Ae. aegypti in the present study, where the few survivors remained as larvae. This result is very important for the evaluation of the potential use of these compounds as insecticides, because $A e$. aegypti treated with a successful commercial analogue of
$\mathrm{JH}$ (methoprene) also remained as larvae or died as pupae, without emerging as adults (Braga et al. 2005a,b).

Finally, the tetranortriterpenoid, azadirachtin, purified from Azadirachta indica A. (Juss.) (Meliaceae) acts on the insect neurosecretory cells. Juvenile forms after contact with this product remain irreversibly in the larval stage (Garcia et al. 1986, Mulla \& Su 1999), as similarly observed after Ae. aegypti treatment with clusianone isolated from $C$. fluminensis. Likewise, benzophenone-3 used in UV filters affects embryogenesis by delaying hatching and mimicking the action of ecdysone, thereby disrupting the insect endocrinological equilibrium (Ozáez et al. 2014). Therefore, evidence from previous studies and for clusianone indicates that many naturally-occurring plant insect control agents affect the pest endocrine homeostasis to kill, delay or interrupt the development of their target species.

In conclusion, the present research shows, for the first time, the insecticidal activity of the benzophenone, clusianone, against mosquitoes and represents a promising start for the development of natural plant products for the control of insect vectors of tropical diseases. 

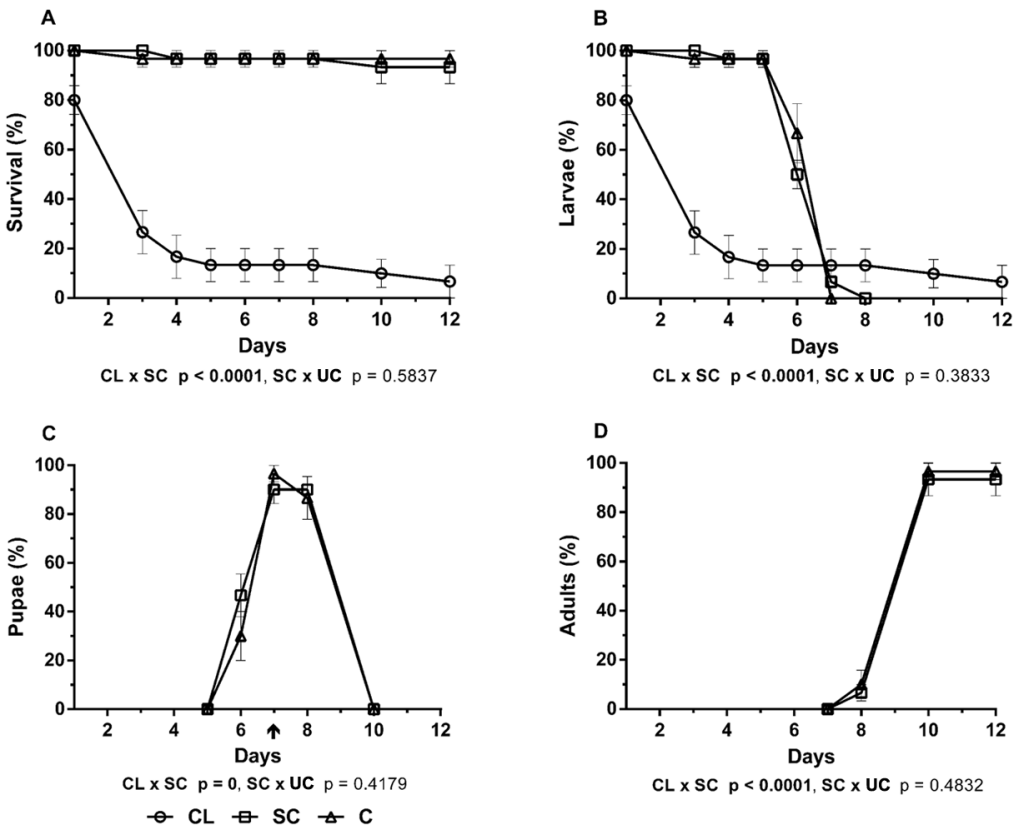

Fig. 4: effects of clusianone (CL) isolated from Clusia fluminensis on survival (A) and development of larvae (B), pupae (C) and adult (D) of Aedes aegypti at different days after experimental treatment (CL) compared with the solvent control (SC) that was compared with untreated control (UC). The assays were executed and analysed as in the Fig. 1 legend and Materials and Methods.

\section{ACKNOWLEDGEMENTS}

To Felipe Leite and Jefferson OC de Oliveira (UFF), for technical assistance, and to the command of Forte Barão do Imbuhy (21st Group of Field Artillery), for permission to collect C. fluminensis.

\section{REFERENCES}

Bastos MS, Figueiredo RMP, Ramasawmy R, Itapirema E, Gimaque JBL, Santos LO, Figueiredo LTM, Mourão MPG 2012. Simultaneous circulation of all four dengue serotypes in Manaus, state of Amazonas, Brazil in 2011. Rev Soc Bras Med Trop 45: 393-394.

Beatty ME, Stone A, Fitzsimons DW, Hanna JN, Lam SK, Vong S, Guzman MG, Mendez-Ganvan JF, Halstead SB, Letson GW, Kuritsky J, Mahoney R, Margplis HS 2010. Best practices in dengue surveillance: a report from the Asia-Pacific and Americas dengue prevention boards. PLoS Negl Trop Dis doi: 10.1371/journal.pntd.0000890.

Beerhues L, Liu B 2009. Biosynthesis of biphenyls and benzophenones - Evolution of benzoic acid-specific type III polyketide synthases in plants. Phytochemistry 70: 1719-1727.

Belinato TA, Martins AJ, Lima JBP, Valle D 2013. Effect of triflumuron, a chitin synthesis inhibitor on Aedes aegypti, Aedes albopictus and Culex quinquefasciatus under laboratory conditions. Parasites \& Vectors doi: 10.1186/1756-3305-6-83.

Bhatt S, Gething PW, Brady OJ, Messina JP, Farlow AW, Moyes CL, Drake JM, Brownstein JS, Hoen AJ, Sankoh O, Myers MF, George DB, Jaenisch T, Wint GRW, Simmons CP, Scott TW, Farrar JJ, Hay SI 2013. The global distribution and burden of dengue. Nature 496: 504-507.

Biondi A, Mommaerts V, Smagghe G, Viñuela E, Zappalà L, Desneux $\mathrm{N} 2012$. The non-target impact of spinosyns on beneficial arthropods. Pest Manag Sci 68: 1523-1536.
Bittrich V 2010. Clusiaceae. Lista de espécies da flora do Brasil. Jardim Botânico do Rio de Janeiro. Available from: floradobrasil. jbrj.gov.br/2010/FB000089.

Bowers WS, Ohta T, Cleere JS, Marsella PA 1976. Discovery of insect anti-juvenile hormones in plants. Science 193: 542-547.

Brady OJ, Gething PW, Bhatt S, Messina JP, Brownstein JS, Hoen AJ, Moyes CL, Farlow AW, Scott TW, Hay SI 2012. Refining the global spatial limits of dengue virus transmission by evidencebased consensus. PLoS Neglect Trop Dis doi: 10.1371/journal. pntd.0001760.

Braga IA, Lima JBP, Soares SS, Vale D 2004. Aedes aegypti resistance to temephos during 2001 in several municipalities in the states of Rio de Janeiro, Sergipe and Alagoas, Brazil. Mem Inst Oswaldo Cruz 99: 199-203.

Braga IA, Valle D 2007. Aedes aegypti: surveillance, resistance monitoring and control alternatives in Brazil. Epidemiol Serv Saude 16: 295-302.

Braga IM, Mello CB, Montella IR, Lima JBP, Martins AJ, Medeiros PFV, Valle D 2005a. Effectiveness of methoprene, an insect growth regulator, against temephos-resistant Aedes aegypti populations from different Brazilian localities, under laboratory conditions. J Med Entomol 42: 830-837.

Braga IM, Mello CB, Peixoto AA, Valle D 2005b. Evaluation of methoprene effect on Aedes aegypti (Diptera: Culicidae) development in laboratory conditions. Mem Inst Oswaldo Cruz 100: 435-440.

Cantrell CL, Dayan FE, Duke SO 2012. Natural products as sources for new pesticides. J Nat Prod 75: 1231-1242.

Carvalho AFU 2011. Toxicity of Brazilian plant seed extracts to two strains of Aedes aegypti (Diptera: Culicidae) and non-target animals. J Med Entomol 48: 846-851. 
Cetin H, Yanikoglu A, Cilek JE 2011. Larvicidal activity of selected plant hydrodistillate extracts against the house mosquito, Culex pipiens, an West Nile virus vector. Parasitol Res 108: 943-948.

R Development Core Team 2014. R: a language and environment for statistical computing. Available from: R-project.org/.

da Silva FC, de Barros FMC, Prophiro JS, da Silva OS, Pereira TN, Bordignon SAL, Eifler-Lima VL, von Poser GL 2013a. Larvicidal activity of lipophilic extract of Hypericum carinatum (Clusiaceae) against Aedes aegypti (Diptera: Culicidae) and benzophenones determination. Parasitol Res 112: 2367-2371.

da Silva OS, da Silva FC, de Barros FMC, da Silva JLR, Bordignond SAL, Eifler-Limab VL, von Poserb GK, Prophiroc JS 2013b. Larvicidal and growth-inhibiting activities of extract and benzopyrans from Hypericum polyanthemum (Guttiferae) against Aedes aegypti (Diptera: Culicidae). Ind Crop Prod 45: 236-239.

Delle Monache F, Delle Monache G, Gács-Baitz E 1991. Prenylated benzophenones from Clusia sandinensis. Phytochemistry 30: 2003-2005.

Dick OB, San Martín JL, Montoya RH, Diego J, Zambrano B, Dayan GH 2012. The history of dengue outbreaks in the Americas. Am J Trop Med Hyg 87: 584-593.

Erguler K 2012. Barnard: Barnard's Unconditional Test. R package version 1.3. Available from: erguler.kamil@ucy.ac.cy.

Fontoura NG, Bellinato DF, Valle D, Lima JBP 2012. The efficacy of a chitin synthesis inhibitor against field populations of organophosphate-resistant Aedes aegypti in Brazil. Mem Inst Oswaldo Cruz 107: 387-395.

Garcia ES, Uhl M, Rembold H 1986. Azadirachtin, a chemical probe for the study of moulting processes in Rhodnius prolixus. $Z$ Naturf 41: 771-775.

Georghiou GP 1972. The evolution of resistance to pesticides. Annu Rev Ecol Syst 3: 133-168.

Gubler DJ 2011. Dengue, urbanization and globalization: the unholy trinity of the 21st century. Trop Med Int Health 39: 3-11.

Isman NB 2006. Botanical insecticides, deterrents and repellents in modern agriculture and an increasingly regulated world. Annu Rev Entomol 51: 45-66.

Li WQ, Zhang ZJ, Nan X, Liu YQ, Hu GF, Yu HT, Zhao XB, Wua D, Yana LT 2014. Design, synthesis and bioactivity evaluation of novel benzophenone hydrazone derivatives. Pest Manag Sci 70: 667-673.

Maciel-de-Freitas R, Avendanho FC, Santos R, Sylvestre G, Araújo SC, Lima JBP, Martins AJ, Coelho GE, Valle D 2014. Undesirable consequences of insecticide resistance following Aedes aegypti control activities due to a dengue outbreak. PloS One doi: 10.1371/journal.pone.0092424.

Middleton WJ, Chadds F, inventors. Benzophenone hydrazones containing peruoroalkyl, peruoroalkoxy and peruoroalkylthio substituents. United States patent US 3732307, 1970 Set 24, 1973 May 8.
Miresmailli S, Isman MB 2014. Botanical insecticides inspired by plant-herbivore chemical interactions. Trends Plant Sci 19: 29-35.

Mulla MS, Su T 1999. Activity of biological effects of neem products against arthropods of medical and veterinary importance. $J \mathrm{Am}$ Mosq Control Assoc 15: 133-152.

Narahashi T 2000. Neuroreceptors and ion channels as the basis for drug action: past, present and future. J Pharmacol Exp Ther 294: 1-26.

Navarro DMAF, Silva PCB, Silva MFR, Napoleao TH, Paiva PMG 2015. Larvicidal activity of plant and algae extracts, essential oils and isolated chemical constituents against Aedes aegypti. Nat Prod J 3: 268-291.

Oliveira EC, Anholeti MC, Domingos TF, Faioli CN, Sanchez EF, Paiva SR, Fuly AL 2014. Inhibitory effect of the plant Clusia fluminensis against biological activities of Bothrops jararaca snake venom. Nat Prod Commun 9: 21-25.

Ozáez I, Martínez-Guitarte JL, Morcillo G 2014. The UV filter benzophenone 3 (BP-3) activates hormonal genes mimicking the action of ecdysone and alters embryo development in the insect Chironomus riparius (Diptera). Environ Pollut 192: 19-26.

Porto ALM, Machado SMF, de Oliveira CMA, Bittrich V, Amaral MDCE, Marsaioli AJ 2000. Polyisoprenylated benzophenones from Clusia floral resins. Phytochemistry 55: 755-768.

Powell JR, Tabachnick WJ 2013. History of domestication and spread of Aedes aegypti - A Review. Mem Inst Oswaldo Cruz 108 (Suppl. I): 11-17.

Ranganatha VL, Begum AB, Prashanth T, Gurupadaswamy HD, Madhu SK, Shivakumar S, Khanum SA 2013. Synthesis and larvicidal properties of benzophenone comprise indole analogues against Culex quinquefasciatus. Drug Invent Today 5: 275-280.

Reegan AD, Gandhi MR, Paulraj MG, Ignacimuthu S 2014. Larvicidal activity of medicinal plant extracts against Culex quinquefasciatus Say and Aedes aegypti mosquitoes (Diptera: Culicidae). Int J Pure Appl Zool 2: 205-210.

Rothman KJ 1990. No adjustments are needed for multiple comparisons. Epidemiology 1: 43-46.

Shaalan EAS, Canyon D, Younes MWF, Abdel-Wahab H, Mansour AH 2005. A review of botanical phytochemicals with mosquitocidal potential. Environ Int 31: 1149-1166.

Silva MCA, Heringer AP, Figueiredo MR, Paiva SR 2012. Separation of clusianone from Clusia fluminensis Planch. and Triana (Clusiaceae) by high speed counter-current chromatography (HSCCC). J Liq Chromatogr Relat Technol 35: 2313-2321.

Vontas J, Kioulos E, Pavlidi N, Morou E, Della Torre A, Ranson H 2012. Insecticide resistance in the major dengue vectors Aedes albopictus and Aedes aegypti. Pestic Biochem Phys 104: 126-131. 